\title{
Unintentional Carbon Monoxide Poisoning From an Unlikely Source
}

\author{
Tim Struttmann, MSPH, Amy Scheerer, MSPH, T. Scott Prince, MD, and \\ Linda A. Goldstein, $P b D$
}

Carbon monoxide poisoning is an occupational health risk across a broad range of industries and vocations (eg, firefighters, tollbooth operators, miners, mechanics). In 1995 carbon monoxide poisoning was the cause of 42 occupational fatalities in the United States. ${ }^{1}$ In 1993,862 nonfatal cases of carbon monoxide poisoning resulted in days away from work. The manufacturing and retail trade industries accounted for the largest percentage of carbon monoxide poisonings (27.3 percent and 24.2 percent, respectively); the agriculture-forestry-fishing industry accounted for 3.1 percent. ${ }^{2}$ Although these values appear to represent carbon monoxide poisoning at work as a rare event, the percentages are highly conservative. The symptoms of carbon monoxide poisoning are nonspecific, and many nonfatal cases of carbon monoxide exposure go undetected. ${ }^{3}$ It has been estimated that one third of all carbon monoxide poisonings are undiagnosed. 4

The most common sources of carbon monoxide are fire, vehicle exhaust, gasoline-powered engines (especially if operated in enclosed spaces), and poorly ventilated or faulty furnaces and heaters. ${ }^{5}$ Most work-related carbon monoxide exposures are caused by exhaust from poorly ventilated vehicles and by gasoline-powered machines operated in enclosed areas. Carbon monoxide poisonings among construction workers have involved gasoline-powered washers in an underground parking garage, gasoline-powered forklifts in an enclosed warehouse, and gasoline-fueled

Submitted 26 January 1998.

From the Kentucky Injury Prevention and Research Center (TS, AS), and the Southeast Center for Agricultural Health and Injury Prevention (TS, TSP), and the Department of Preventive Medicine and Environmental Health (TSP), University of Kentucky Chandler Medical Center, Lexington; and the Center for Injury Research and Control (LAG), University of Pittsburgh. Address reprint requests to Tim Struttmann, MSPH, Kentucky Injury Prevention and Research Center, 333 Waller Ave, Suite 202, Lexington, KY 40504-2915.

This work was supported by the NIOSII Cooperative Agreement U06/CCU412957-01. saws. ${ }^{6}$ In other industries, carbon monoxide poisonings have been reported among workers using gasoline-powered pressure washers to clean animal housing on Iowa farms ${ }^{7}$ and among workers using propane-powered floor burnishers in a Vermont pharmacy. ${ }^{8}$

This report documents an unusual case of carbon monoxide poisoning in that the incident occurred outdoors while a farmer was setting tobacco plants on a family farm. An extensive review of the literature found no cases of carbon monoxide poisoning from tractor exhaust in an open field.

\section{Case Report}

In June 1997 at approximately 1 PM, a 37-year-old female farmer (the victim), her husband, and brother-in-law began planting tobacco in their 4.5 -acre field. The temperature exceeded $90^{\circ} \mathrm{F}$, and the air was humid with little or no breeze. While the victim's husband drove the gasolinepowered tractor pulling the attached tobacco setter, the victim and her brother-in-law rode sideby-side on the setter (Figure 1). Seated with their backs to the tractor, they were exposed to the backward venting of exhaust from the exhaust pipe underneath the tractor. The victim was seated closest to the exhaust pipe.

By $4 \mathrm{PM}$, the victim and her brother-in-law reported having headaches; the victim also complained of dizziness and fatigue. Although her brother-in-law stopped working at 4:30 PM, the victim insisted on finishing despite her increasingly severe headache, drowsiness, and dizziness. She began to miss setting plants, a task requiring handeye coordination. At 6:30 PM she collapsed on the tray of plants in front of her on the setter.

The victim's husband notified emergency medical services at 7:30 PM, reporting that he thought his wife had carbon monoxide poisoning. At 7:42 PM her blood pressure was $140 / 100 \mathrm{mmH}$, heart rate 96 beats per minute, and respiratory rate 20 per minute. She complained of dizziness, lightheadedness, headache, nausea, a pounding heart, 


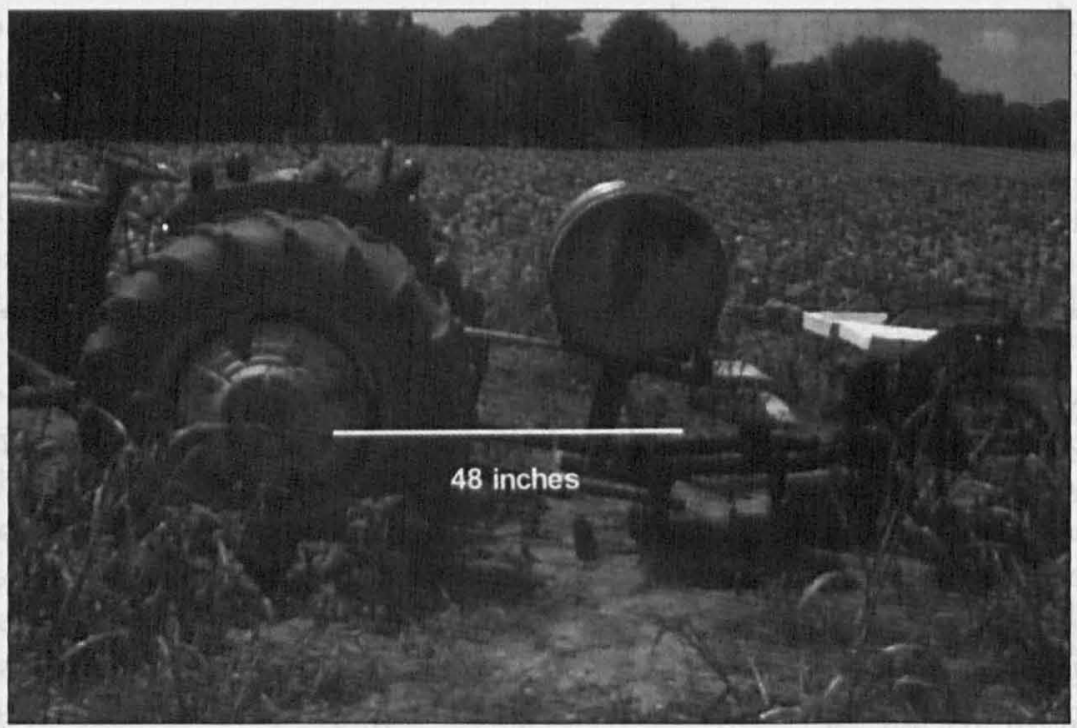

Figure 1. Tractor and setter.

Distance from distal end of exhaust pipe to victim's seat on tobacco setter is approximately 48 inches.

ted carbon monoxide at levels well above the ceiling limit of $200 \mathrm{ppm}$ recommended by the National Institute for Occupational Safety and Health. ${ }^{9}$ These levels should not be exceeded at any time.

\section{Discussion}

Carbon monoxide is an insidious occupational health hazard.

and wheezing. At the hospital emergency department, arterial blood gas measurements, an electrocardiogram, a complete blood cell count, and a chemistry panel were ordered. She was treated with 100 percent oxygen through a nonrebreathing mask and was given intravenous fluids. Albuterol was administered by nebulizer because she had a history of asthma. By the time blood was drawn for blood gas analysis, nearly 3 hours had elapsed since carbon monoxide exposure, and she had been on 100 percent oxygen for 36 minutes. Her carboxyhemoglobin level was 23.3 percent; hyperbaric oxygen treatment was not prescribed. All other tests were within normal limits. At 11:05 PM her carboxyhemoglobin level was 7.2 percent; she was discharged from the emergency department at 12:10 AM.

Case follow-up included systematic carbon monoxide sampling of the tractor's exhaust system. A monitor was placed in the location where a worker would sit on the tobacco setter (about 48 inches from the tractor's exhaust pipe; Figure 1) while the tractor remained in a stationary position with the engine running. During a 15 -minute period, the exhaust averaged $477 \mathrm{ppm}$ of carbon monoxide. Sampling was also conducted in conditions that simulated planting procedures. The result was $384 \mathrm{ppm}$ of carbon monoxide during a 15-minute period.

Four additional gasoline-powered tractors with the same exhaust configuration were tested; these tractors ranged from 29 to 34 horsepower and were manufactured between 1947 and 1979. Results showed that three of the four tractors emit-
The gas accumulates quickly, even in well-ventilated areas, and toxic effects ensue rapidly. Symptoms can manifest suddenly but are relatively nonspecific (eg, headache, dizziness, weakness, nausea, visual disturbances, and confusion). ${ }^{5}$ Carbon monoxide induces its toxic effects by binding to hemoglobin, with an affinity 240 times greater than oxygen, to form carboxyhemoglobin. The net effect is a reduction in the oxygen-carrying capacity of the blood.

The clinical signs and symptoms of carbon monoxide poisoning vary, but in general, symptom severity correlates with carboxyhemoglobin level (Table 1). ${ }^{5,10,11}$ Symptom severity and carboxyhemoglobin levels depend on (1) concentration of carbon monoxide in the environment, (2) duration of carbon monoxide exposure, and (3) interval between exposure and clinical assessment. Normal carboxyhemoglobin concentrations are 2 percent or less for nonsmokers and 9 percent or less for smokers. ${ }^{12}$ The victim reported having smoked four to five cigarettes on the day of the incident; she has a 15 -year history of smoking a pack of cigarettes a day.

Given the nonspecificity of its symptoms, victims can mistake carbon monoxide poisoning for the flu, heat exhaustion, and food or pesticide poisoning, among other similar ailments, and not seek medical treatment. For the same reason, physicians frequently misdiagnose the condition. ${ }^{5,11,13}$ In this report, the victim and family members had used the tractor-setter routinely, and none reported symptoms of carbon monoxide poisoning. The victim's brother-in-law could have ex- 
perienced a mild case of carbon monoxide poisoning, though he reported having only a headache.

Although measuring carboxyhemoglobin levels is considered useful for determining the severity of exposure to carbon monoxide, there is some debate regarding its reliability. ${ }^{10,11,14} \mathrm{Re}-$ sults can be misleading in that they do not reflect severity of the initial exposure because of time elapsed or treatment begun after the victim was removed from the carbon monoxide source. ${ }^{10} \mathrm{In}$ this report, nearly 3 hours passed between the exposure and her carboxyhemoglobin measurement of 23.3 percent in the emergency department. By back-extrapolation, assuming an 80minute half-life for carbon monoxide in 100 percent oxygen and a 320-minute half-life in normal air, ${ }^{15}$ a carboxyhemoglobin level of 41 percent was estimated for the end of exposure (David Dankovic, personal communication, 16 Dec 1997). Thus, in addition to measuring carboxyhemoglobin levels, obtaining a comprehensive patient history is important. ${ }^{11}$ In this report, there was little ambiguity about the cause of the victim's symptoms. Nevertheless, an occupational history provided critical details about exposure duration, smoking behavior, and other complicating factors.

Treatment for carbon monoxide poisoning consists of the immediate removal of the victim from the source. In ambient air, the half-life of carbon monoxide is 320 minutes. The use of 100 percent oxygen reduces this half-life to $80 \mathrm{~min}$ utes. Under hyperbaric conditions ( 2.5 to $3 \mathrm{~atm}$ ), the half-life of carbon monoxide is reduced even further, to about 23 minutes. ${ }^{15}$ Using 100 percent oxygen to treat carbon monoxide poisoning is well-accepted because it is safe, convenient, and inexpensive ${ }^{10}$; the use of hyperbaric oxygen treatment, however, remains highly controversial.

Some advocate the wider use of hyperbaric oxygen treatment because it offers rapid relief and might prevent delayed neurologic sequelae. ${ }^{14,16-18}$ Others emphasize a more conservative approach with consideration of a variety of factors, including symptom severity, comorbidity, and distance to the nearest hyperbaric oxygen facility (Hampson et al ${ }^{19}$ discuss this approach in detail). The Undersea and Hyperbaric Medical Society recommends that patients with carboxyhemoglobin levels of 25 percent or greater be treated with hyperbaric oxygen if it is readily available; patients with carboxyhe-
Table 1. Symptoms and Signs Associated With Various Levels of Carbon Monoxide Poisoning.

\begin{tabular}{cl}
\hline $\begin{array}{l}\text { Carboxy- } \\
\text { hemoglobin } \\
\text { Level }\end{array}$ & Symptoms and Signs \\
\hline $0 \%-10 \%$ & None in healthy persons \\
$10 \%-20 \%$ & $\begin{array}{l}\text { Ieadache, dyspnea on mild exertion } \\
\text { Throbbing headache, nausea or vomiting } \\
\text { (or both), fatigability and irritability, weak }\end{array}$ \\
$30 \%-30 \%$ & $\begin{array}{l}\text { ness, difficulty concentrating } \\
\text { wevere headache, dizziness, fatigue and } \\
\text { thought processes }\end{array}$ \\
$40 \%-50 \%$ & $\begin{array}{l}\text { Tachypnea, tachycardia, syncope, confusion } \\
\text { Respiratory failure, collapse, intermittent } \\
\text { convulsions or seizures, coma } \\
\text { Respiratory failure, severe hypotension, }\end{array}$ \\
$50 \%-60 \%$ & $\begin{array}{l}\text { coma, frequently fatal } \\
\text { Coma, rapidly fatal }\end{array}$ \\
\hline
\end{tabular}

Modified from Dolan, ${ }^{5}$ Olson, ${ }^{10}$ and Ilano and Raffin. ${ }^{11}$

moglobin levels of 40 percent or greater should be treated with hyperbaric oxygen even if it requires transport. ${ }^{14}$ Nevertheless, no universally approved guidelines exist for the use of hyperbaric oxygen in treating carbon monoxide poisoning.

This report suggests that workers might not be aware of the risks of carbon monoxide poisoning associated with the use of gasoline-powered engines, especially outdoors. Such risks can be reduced by using a tractor with an upward exhaust system or through engineering modifications, such as altering the exhaust system to vent fumes upward. Reconfiguring a tractor in this manner would cost about $\$ 600$ plus installation. If this alternative is financially prohibitive, workers can limit their exposure to carbon monoxide by taking frequent breaks, rotating their positions on the setter, and getting off the setter if any symptoms of carbon monoxide intoxication appear. Primary prevention also includes proper engine maintenance, exhaust system inspections, and emissions testing.

Educational initiatives would include increasing awareness about the potential hazards associated with the use of gasoline-powered equipment even outdoors, alerting workers to the symptoms of carbon monoxide poisoning, and putting warning labels on equipment. Health care providers should be aware of the occupational risk of exposure among their patients, especially in rural areas where carbon-monoxide-producing equipment is 
used routinely. Health care providers play a critical role in efforts to reduce work-related carbon monoxide poisonings. This diagnosis should be considered when a patient complains of nonspecific symptoms, and a thorough occupational history should be taken. Physicians can also consult with patients at risk about the potential hazards of carbon monoxide and about prevention strategies.

By continuing agricultural injury surveillance activities, health care providers can begin to understand the magnitude of carbon monoxide poisoning as an occupational hazard. Only by developing effective prevention strategies will it be possible to reduce the incidence of carbon monoxide poisoning.

Vickie Brandt, RN, coordinated the investigation of this case.

\section{References}

1. Census of fatal occupational injuries. Washington, DC: US Department of Labor, Bureau of Labor Statistics, 1996.

2. Occupational injuries and illnesses: counts, rates, and characteristics, 1993. Washington, DC: US Department of Labor, Bureau of Labor Statistics, 1996. (Bulletin 2478.)

3. Thom SR, Keim LW. Carbon monoxide poisoning: a review epidemiology, pathophysiology, clinical findings, and treatment options including hyperbaric oxygen therapy. $\mathrm{J}$ Toxicol Clin Toxicol 1989;27:141-56.

4. Heckerling PS, Leikin JB, Maturen A, Terzian CG, Segarra DP. Screening hospital admissions from the emergency department for occult carbon monoxide poisoning. Am J Emerg Med 1990;8:301-4.

5. Dolan MC. Carbon monoxide poisoning. CMAJ $1985 ; 133: 392-9$.

6. Carbon monoxide poisoning from use of gasolinefueled power washers in an underground parking garage-District of Columbia, 1994. MMWR Morb Mortal Wkly Rep 1995;44:356-7, 363-4.
7. Unintentional carbon monoxide poisoning from indoor use of pressure washers-Iowa, January 1992 January 1993. MMWR Morb Mortal Wkly Rep 1993;42:777-85.

8. Carbon monoxide poisoning associated with a propane-powered floor burnisher-Vermont, 1992. MMWR Morb Mortal Wkly Rep 1993;42:726-8.

9. NIOSH pocket guide to chemical hazards. Washington, DC: US Department of Health and Human Services, Public Health Service, Centers for Disease Control and Prevention, National Institute for Occupational Safety and Health, 1994. (NIOSH publication no. 94-116.)

10. Olson KR. Carbon monoxide poisoning: mechanisms, presentation, and controversies in management. J Emerg Med 1984;1:233-43.

11. Ilano AL, Raffin TA. Management of carbon monoxide poisoning. Chest 1990;97:165-9.

12. Amdur MO, Doull J, Klaassen CD. Casarett and Doull's toxicology: the basic science of poisons. 4th ed. New York: McGraw-Hill, 1991.

13. Barret L, Danel V, Faure J. Carbon monoxide poisoning, a diagnosis frequently overlooked. J Toxicol Clin Toxicol 1985;23:309-13.

14. Martindale LG. Carbon monoxide poisoning: the rest of the story. J Emerg Nurs 1989;15(2 Pt 1):101-4.

15. Peterson JE, Stewart RD. Absorption and elimination of carbon monoxide by inactive young men. Arch Environ Health 1970;21:165-71.

16. Myers RA, Snyder SK, Linberg S, Cowley RA. Value of hyperbaric oxygen in suspected carbon monoxide poisoning. JAMA 1981;246:2478-80.

17. Mathieu D, Nolf M, Durocher A, Saulnier F, Frimat $\mathrm{P}$, Furon $\mathrm{D}$, et al. Acute carbon monoxide poisoning. Risk of late sequelae and treatment by hyperbaric oxygen. J Toxicol Clin Toxicol 1985;23:315-24.

18. Norkool DM, Kirkpatrick JN. Treatment of acute carbon monoxide poisoning with hyperbaric oxygen: a review of 115 cases. Ann Emerg Med 1985;14: 1168-71.

19. Hampson NB, Dunford RG, Kramer CC, Norkool DM. Selection criteria utilized for hyperbaric oxygen treatment of carbon monoxide poisoning. J Emerg Med 1995;13:227-31. 